\title{
Rejuvenation of seismic data in Santos and Campos Basins with Full Waveform Inversion and high-resolution imaging
}

Alejandro Alcudia-Leon, Armando Sosa, Sriram Arasanipalai, Bruno Virlouvet, and Hermann Lebit; PGS.

Copyright 2019, SBGf - Sociedade Brasileira de Geofísica

This paper was prepared for presentation during the $16^{\text {th }}$ International Congress of the Brazilian Geophysical Society held in Rio de Janeiro, Brazil, 19-22 August 2019.

Contents of this paper were reviewed by the Technical Committee of the $16^{\text {th }}$ International Congress of the Brazilian Geophysical Society and do not necessarily represent any position of the SBGf, its officers or members. Electronic reproduction or storage of any part of this paper for commercial purposes without the written consent of the Brazilian Geophysical Society is prohibited.

\section{Abstract}

Two case studies illustrate the value of rejuvenating legacy seismic data libraries for better understanding and delineation of the subsurface in both the Santos and Campos Basins. This was achieved by utilizing the full wavefield (refractions and reflections) for Full Waveform Inversion (FWI) in a data-driven velocity model building (VMB) workflow for enhanced depth imaging. The first case study discusses high-resolution regional imaging over a large swath of the Santos Basin. The second case study discusses dual-azimuth reservoir imaging of the Roncador field in the Campos Basin.

\section{Introduction}

Seismic data have many applications throughout the life of the exploration and production asset; from regional reconnaissance to prospect maturation and field development. However, the impact of seismic data at every stage in the life of the asset is closely linked to the quality, resolution and fidelity of the data. These kind of applications represent a major goal for most operators around the world, including Brazil, and require superior seismic data.

High quality seismic data is only possible through continuing innovation in seismic acquisition technology, processing workflows and imaging techniques. The demand for high quality seismic data and the increase of cost-effective computer power enabled the deployment of sophisticated seismic processing and imaging algorithms. For example, Full Waveform Inversion (FWI) has recently emerged as one of the most efficient tools for estimating subsurface model parameters. FWI was introduced in the early 1980 s by Tarantola but it had to wait almost 30 years to achieve widespread acceptance in the seismic industry. Today, FWI is commonly used to invert for the velocity model.

The continuous effort in development and optimization of seismic processing and imaging algorithms justifies rejuvenating existing seismic data libraries every 3-5 years.

Acquisition and processing of new seismic data can be impractical when time to deliver is critical, or when there is a lot of infrastructure and obstructions. Acquiring new seismic and rejuvenating legacy surveys can be complementary goals. For example, to create richer azimuthal coverage for enhanced illumination of deeper and/or more complex targets. One advantage of reprocessing of legacy surveys is that a project can start at any time.

\section{High-resolution regional imaging in the Santos Basin}

The Santos Basin is one of the most oil prolific areas in the world. Reservoir targets in the Santos Basin are localized in presalt carbonate build-ups underneath heterogeneously Layered Evaporite Sequences (LES) and interbedded with volcanic rocks. The presalt hydrocarbon play in the Santos Basin is a focus for many as Brazil's production from presalt continues to rise. This increasing interest has triggered a demand for high quality seismic data over the Santos Basin.

In 2017, PGS embarked on a large rejuvenation program of its data library in the Santos Basin. More than 34,000 $\mathrm{km}^{2}$ of seismic data from 12 separate streamer surveys were merged into a single, seamless, broadband dataset covering a large swath of the Santos Basin (Figure 1).

One major objective of the reprocessing was to improve the imaging of the presalt stratigraphic signature and rift architecture as these are directly related to the play type characterized by presalt carbonate build-ups along tilted or uplifted fault block highs. Results of this program are also discussed by Lebit et al. (2019) with focus on salt mechanics.

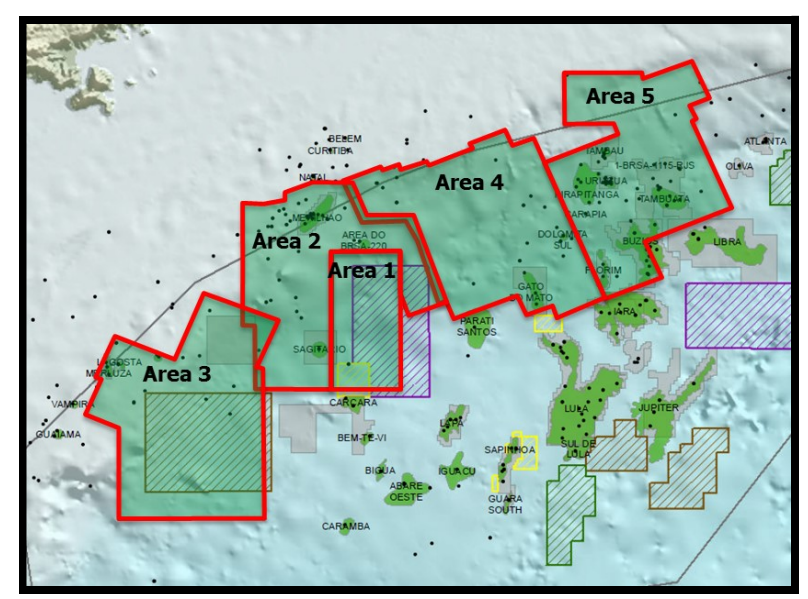

Figure 1. Twelve separate streamer surveys, covering more than $34,000 \mathrm{~km}^{2}$, were merged into a seamless broadband dataset covering a large swath of the Santos Basin. The swath was subdivided into five areas to facilitate project execution. 
On legacy data the presalt reflectivity was not well imaged, so the complexity of the salt and the differing character of the postsalt carbonates needed to be resolved in the Velocity Model Building (VMB) workflow.

The VMB workflow combined geological interpretation, wavelet shift tomography (Sherwood et al., 2011) and FWI through the postsalt clastics, including deep Albian carbonates, intrasalt (LES) and presalt sequences (Figure 2). Kirchhoff Prestack Depth Migration (KPSDM) and Reverse Time Migration (RTM) were used through the VMB workflow to support the geological QC.

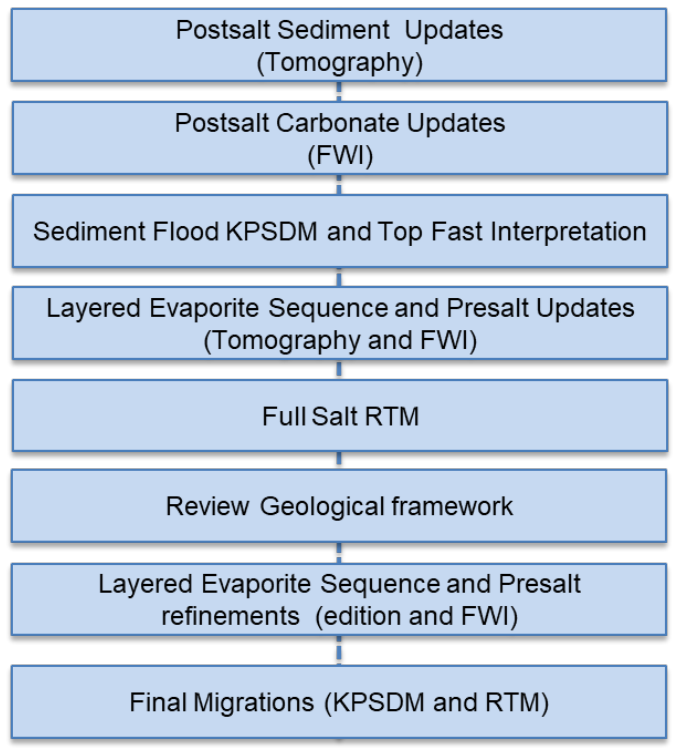

Figure 2. Velocity model building workflow for highresolution regional imaging in the Santos Basin.

FWI inverts for the velocity model by solving a nonlinear inverse problem minimizing the difference between modeled data and recorded field data (Tarantola, 1984). In our case, FWI utilized the full wavefield implementation of Ramos-Martinez et al. (2016). This implementation produces low wavenumber velocity updates at depths where no refracted energy is recorded by using a variation of the Inverse Scattering Imaging Condition (ISIC) of the RTM (Whitmore and Crawley, 2012). It combines refractions and reflections in a single module producing robust updates from shallow to deep.

Most of the project area is deep water and the majority of the surveys were acquired with $6 \mathrm{~km}$ streamers. For this reason, the presence of refractions was limited. The FWI updates in the postsalt clastics and Albian Carbonates were obtained by using both refracted and reflected arrivals. The optimal result was achieved by gradually increasing offset and frequency after a few iterations. The velocity perturbation of FWI was structurally conformable to $6 \mathrm{~km}$ depth, capturing the depth dependent velocity variability within the mega-sequences of the Upper Cretaceous clastic sequences and the Albian carbonates (Figure 3).

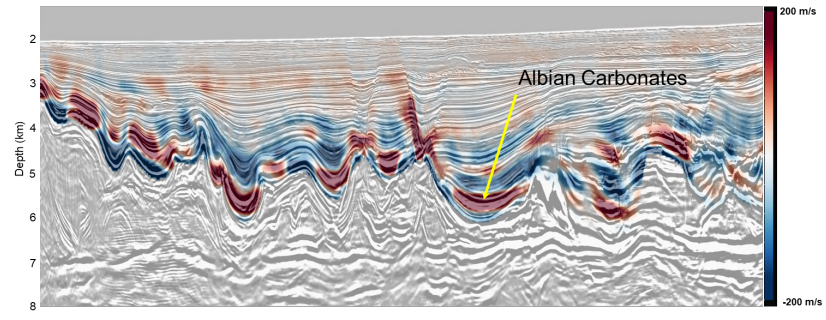

Figure 3. Velocity perturbation of FWI overlaid by the PSDM QC stack showing a structurally conformable velocity update of the postsalt deep carbonate layer.

An accurate Top of Salt (TOS) mask was interpreted on a high-resolution KPSDM stack volume migrated with the final sediment velocities. This mask was necessary to separate the LES from the postsalt clastics and Albian carbonates. Velocity updates in the LES captured the velocity variations due to layering inside the salt bodies, leading to a more accurate Base of Salt (BOS) and presalt imaging.

Velocity updates in the LES and presalt layers were fully data-driven using a combination of wavelet shift tomography and FWI.

Figure 4 shows an example of the intrasalt velocity update using FWI. Several benefits can be observed from this example. Firstly, the velocity perturbation was consistent with the behavior of the intrasalt events in the stack and Common Image Gathers (CIGs). Secondly, the flatness of the intrasalt events was improved in the CIGs after remigration with the updated velocity model. Thirdly, the stack response and continuity of the BOS was improved, which helped simplify the presalt structure.

Based on the robustness of the intrasalt velocity updates, FWI was pushed deeper into the presalt section (Figure 5). The salt and presalt layers were combined into a single model building unit for FWI. This approach removed any dependency on BOS horizon interpretations and avoided a hard velocity boundary between salt and presalt sections. The resolution and accuracy of the velocity model in the salt and presalt sections were improved. After remigration the BOS was stabilized and the presalt events simplified.

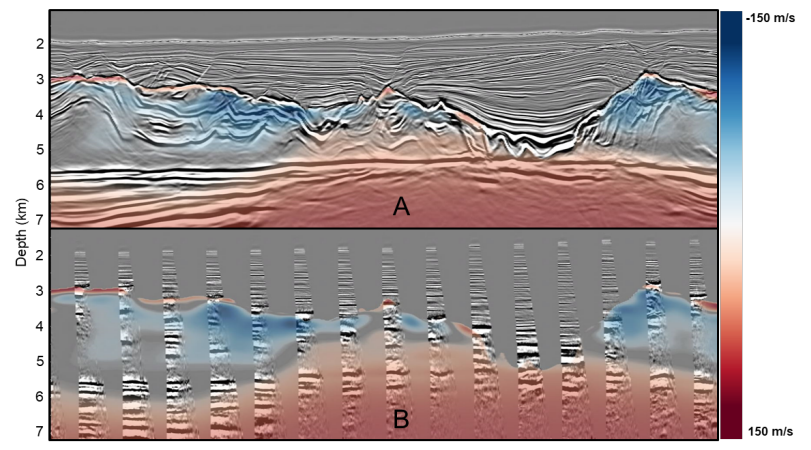

Figure 4. Intrasalt velocity perturbation of FWI overlaid by the PSDM QC stack $(A)$ and CIGs (B). 


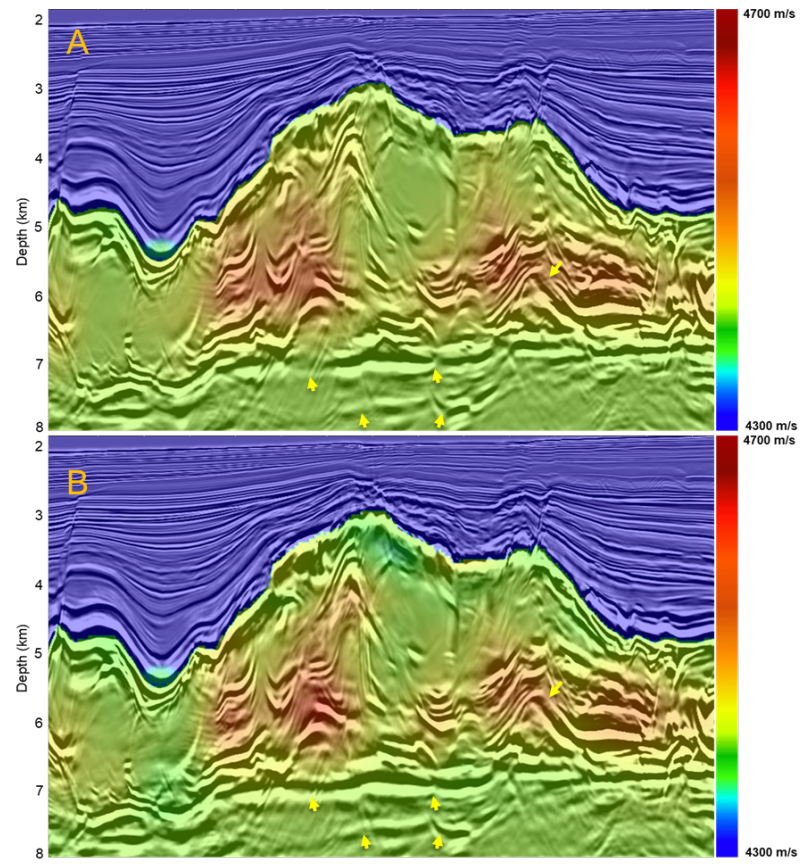

Figure 5. FWI (B) in the salt and presalt improved the resolution and accuracy of velocity model compared to the starting velocity model (A). As a result, the base of salt was stabilized and the presalt events were simplified.

\section{Dual-azimuth reservoir imaging in Roncador field}

The Roncador field is a giant oil and gas field located in the central region of Campos Basin, $125 \mathrm{~km}$ off the coast of Brazil; and $215 \mathrm{~km}$ from the city of Macaé, northeast from Rio de Janeiro (Figure 6). The field has been in production since 1999 with output during May 2018 of around 239,000 barrels of oil equivalent (boe) per day plus around 40,000 boe per day of associated gas (ANP production bulletin, May 2018). Roncador was the largest discovery offshore Brazil in the 1990s and is currently the third largest producing field in Petrobras' portfolio with around 10 billion boe in place and an expected remaining recoverable volume of more than 1 billion boe.

The rejuvenation of seismic data from the Roncador oil field was aimed at revitalizing two existing orthogonal surveys and exploiting their bi-azimuthal diversity: 1) Albacora/Roncador HD3D streamer survey, shot in an east-west direction, and 2) Roncador 3D 4C OBC, shot in a north-south direction. The water depth in the project area ranges from 936 to $2,027 \mathrm{~m}$, and the bathymetry is dominated by incised canyons, draining downslope to the East off the shelf break located to the West.

The main objective of the project was to produce higher quality images of the complex structures in the postsalt and presalt sections of the field by applying an advanced dual-azimuth (DAZ) reprocessing and depth imaging workflow (Figure 7). This workflow was designed to derisk a series of drilling prospects in the Roncador oil field, which are considered fundamental for the sustainable development of the field.

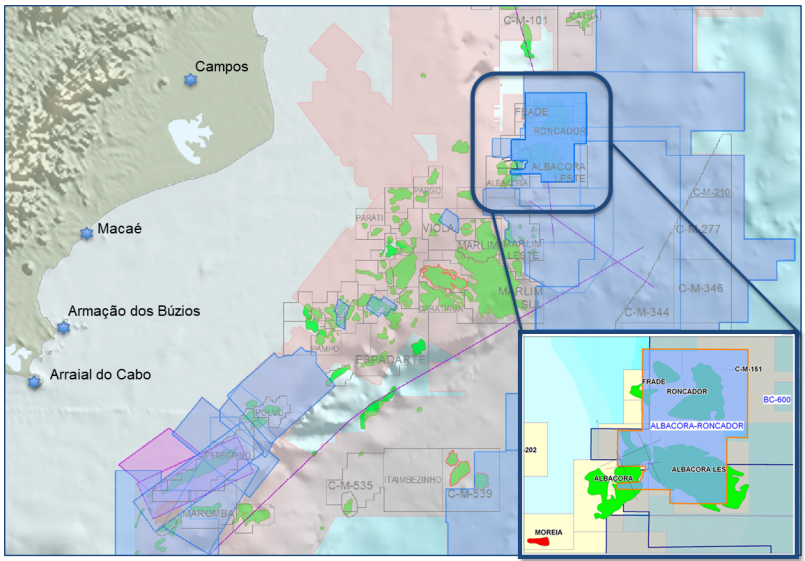

Figure 6. Geographical location of the Roncador field, Campos Basin, offshore Brazil.

The primary geophysical objective was to improve the depth imaging of the lower section of the passive margin sequences around the Roncador production area. Another key target was to enhance the imaging of the postsalt carbonates which form mega-flaps and turtle structures next to the underlying Aptian salt. Finally, optimizing the salt model would upgrade the image quality of both the BOS and underlying faulted presalt sequences.

The VMB in the Roncador area was fully data-driven employing a strategy of iterative model refinement, similar to the previous case study in the Santos Basin. This allowed PGS to extract maximum potential from the available streamer and $\mathrm{OBC}$ data.

The FWI workflow used the full recorded wavefield from both streamer and OBC datasets to resolve the seabed and paleo-canyon's velocities, inserting more resolution and accuracy in the sediment overburden section (Figure 8). The OBC data was used for the initial FWI velocity update with a bandwidth of $2.5-5 \mathrm{~Hz}$ and offsets up to 9 $\mathrm{km}$. This was followed by higher frequency FWI updates using both $\mathrm{OBC}$ and streamer data simultaneously (DAZ FWI), taking advantage of the bi-azimuthal diversity.

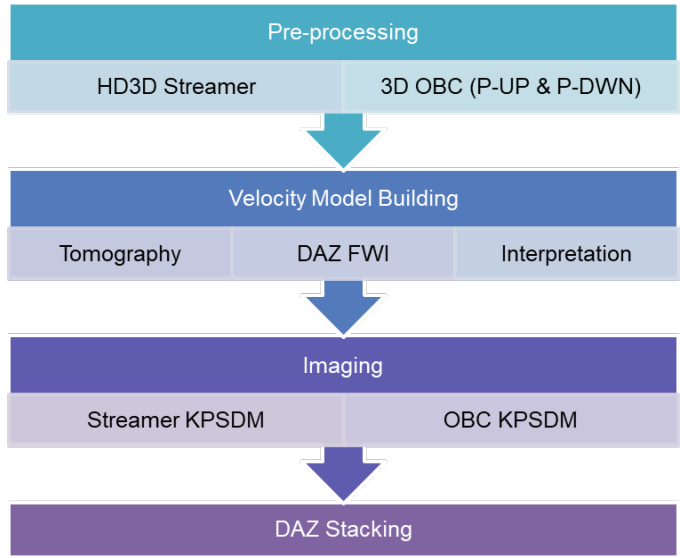

Figure 7. Simplified dual-azimuth reprocessing and depth imaging workflow in Roncador field. 
The streamer survey was acquired with $6 \mathrm{~km}$ cables in deep water, therefore the FWI updates beyond the dualazimuth area were primarily driven by reflections. The limited offsets and lack of coherent frequency signal below $5 \mathrm{~Hz}$ represented a challenge outside the overlapping dual-azimuth area. Detailed starting models were built using both wavelet shift tomography and conventional reflection tomography prior to FWI.

FWI updates in the sediment overburden were achieved with frequency bands ranging from 2 to $9 \mathrm{~Hz}$. As the model converged, the updates from $\mathrm{FWI}$ in the higher frequency runs became smaller in magnitude and fewer iterations were required.

Figure 8 shows that the DAZ FWI updates in the sediment overburden were structurally conformable, capturing the shallow velocity anomalies (paleo-canyons) and the velocity variability of the Marco Azul horizon. These shallow velocity updates led to better structural imaging at the Roncador reservoir level.

The LES and presalt sections were treated as a single model building unit for the FWI update. Overall, the intrasalt velocity updates flattened the BOS. Due to the limitations of the data, the presalt updates were small. A final pass of FWI was applied from the seabed to presalt to refine the velocity model.

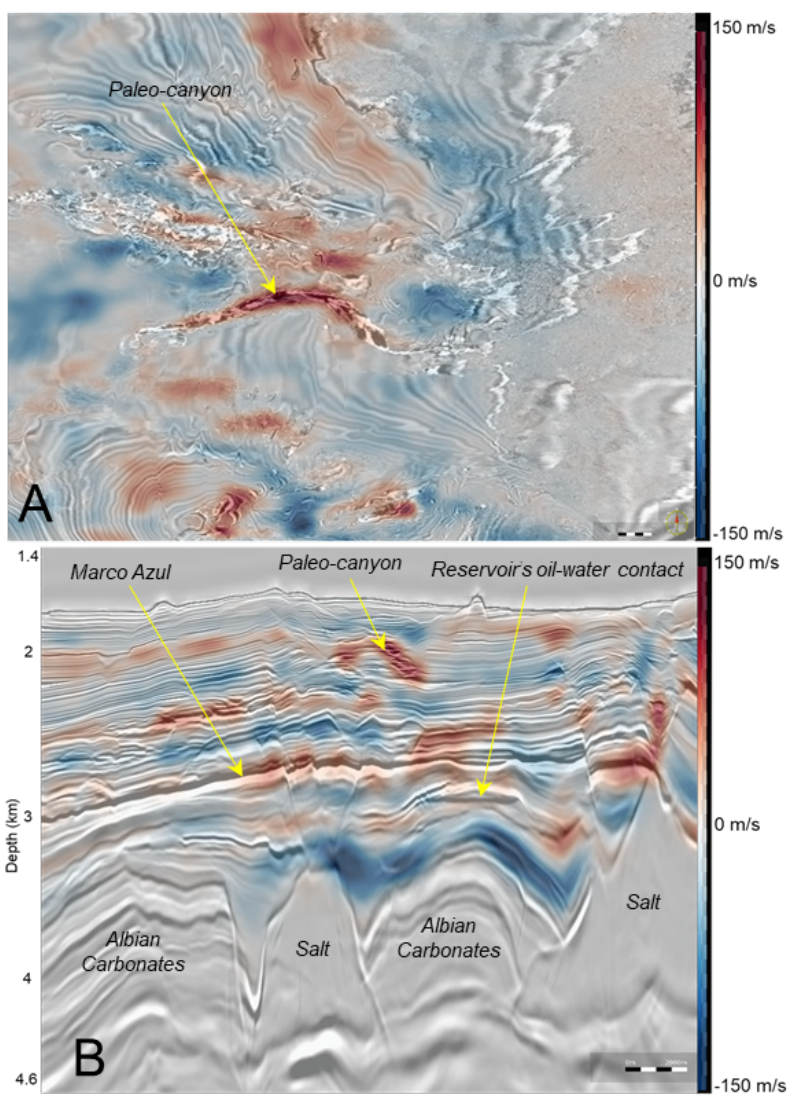

Figure 8. Velocity perturbation of DAZ FWI overlaid by $P S D M$ QC stack. Depth slice at $2 \mathrm{~km}$ depth (A) and crossline section (B) showing that velocity updates of DAZ FWI were structurally conformable and less than +/$150 \mathrm{~m} / \mathrm{s}$.
A clearer image of the postsalt primary targets was achieved through a combination of state-of-the-art time processing, data-driven high-resolution velocity model building and advanced depth imaging. The DAZ reprocessing enhanced the vertical resolution, improved the subsurface illumination, and increased the signal-tonoise ratio at key geological targets when compared to the legacy single-azimuth PSDM (Figure 9).

In addition, significant uplift was achieved in the salt and presalt areas, particularly in the core OBC area where subsurface illumination benefited from the dual-azimuth imaging.

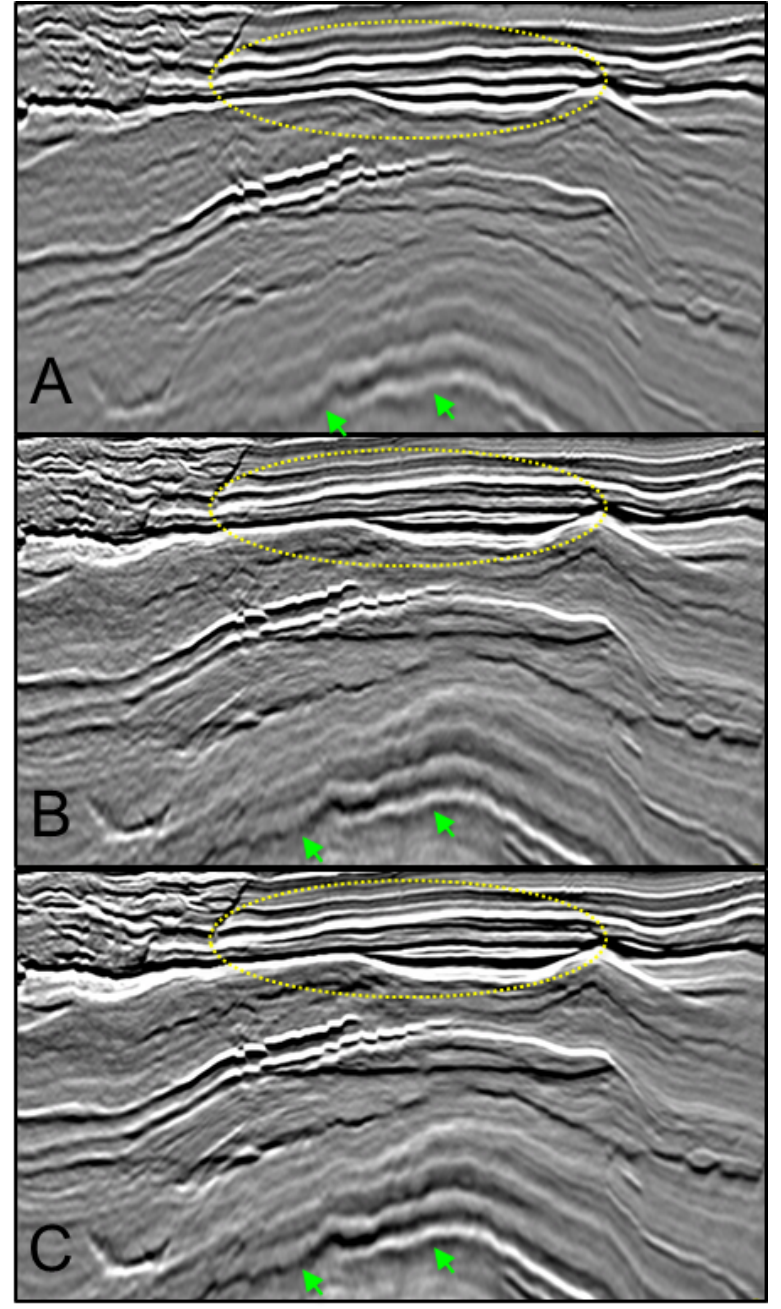

Figure 9. Legacy single-azimuth (streamer) KPSDM (A), reprocessed single-azimuth (streamer) KPSDM (B), and reprocessed dual-azimuth (streamer + OBC) KPSDM (C). The $D A Z$ reprocessing increased vertical resolution (as shown in the yellow oval), improved illumination (green arrows), and increased signal-to-noise ratio at key geological targets 


\section{Conclusions}

The two case studies illustrated the value of rejuvenating legacy seismic data for better understanding and delineation of the subsurface. This was achieved by utilizing the full wavefield for FWI in a data-driven VMB sequence with advanced depth imaging.

Improved imaging in the presalt section was achieved by capturing the velocity variations in the postsalt Albian carbonates and LES through a combination of tomography and FWI. Avoiding a hard velocity boundary at the base of the salt also helped with presalt image continuity.

\section{Acknowledgments}

The authors thank Petrobras for their valuable technical contribution to the successful execution of the Roncador DAZ imaging project and their permission to publish the results. The authors also thank PGS for permission to publish this paper and to use data examples from the Santos Vision rejuvenation program.

\section{References}

Lebit, H., S. Arasanipalai, J. Tilton, P. Ollagnon, and B. Virlouvet, 2019, High-resolution seismic imaging in the Santos Basin, Brazil and its impact on salt mechanics, 16th International Congress of the Brazilian Geophysical Society \& EXPOGEF, Rio de Janeiro, Brazil, 19-22.

Ramos-Martinez, J., S. Crawley, Z. Zou, A.A. Valenciano, L. Qiu, and N. Chemingui, 2016, A robust gradient for long wavelength FWI updates: 76th Annual International Conference and Exhibition, EAGE, Extended Abstracts, Th SRS2 03

Sherwood, J., J. Jiao, H. Tieman, K. Sherwood, C. Zhou, S. Lin, and S. Brandsberg-Dahl, 2011, Hybrid tomography based on beam migration: 81st Annual International Meeting, SEG, Expanded Abstracts, 3979-3983.

Tarantola, A., 1984, Inversion of seismic reflection data in the acoustic approximation: Geophysics, 49, no. 8, 12591266.

Whitmore, N.D., and S. Crawley, S., 2012, Application of RTM inverse scattering imaging conditions: 82nd Annual International Meeting, SEG, Expanded Abstracts, 1-6. 